\title{
NOVEL TECHNIQUE IN CHARACTARIZING A PV MODULE USING PULSE WIDTH MODULATOR
}

\author{
I.M. Mahmoud ${ }^{1}$, S. O. Abdellatif ${ }^{2}$, T. S. Abdelsalam ${ }^{3,4}$,O. E. Abdellatif ${ }^{5}$ \\ ${ }^{1}$ Teaching Assistant, E E. Department, The British University in Egypt, Cairo, Egypt \\ ${ }^{2}$ Assistant Lecturer, E E. Department, The British University in Egypt, Cairo, Egypt \\ ${ }^{3}$ Head of Department, E E. Department, The British University in Egypt, Cairo, Egypt \\ ${ }^{4}$ Assoc. Professor, Electrical Power and Machines Department, Ain Shams University, Cairo, Egypt \\ ${ }^{5}$ Professor, Mechanical Engineering Department, Banha University, Cairo, Egypt
}

\begin{abstract}
The fabrication and characterization of PV modules are always done under standard test conditions (STC). However, The condition of operation are often far from thisstandard conditions. As a result, developing a characterization circuit is considered as a point of interest for researchers. This paper presents a new methodology in characterizing a PV module using an electronic load circuit. The circuit is implemented using a power MOSFET driven by a pulse width modulator (PWM) developed by LABVIEW. The system is tested and its results are validated by comparing it with simulation results performed by Comsol Multiphysics and Matlab. The system shows high accuracy with respect to the previous published work with lower cost and higher simplicity.
\end{abstract}

Keywords: Photovoltaic, Characterization, Electronic load, and Pulse width modulation (PWM)...

\section{INTRODUCTION}

Photovoltaic (PV) represents one of the most promising means of maintaining our energy intensive standard of living while not contributing to global warming and pollution. PV refers to the direct generation of electricity by solar irradiance. The irradiance and the temperature are considered the main environmental parameters that the generated power of the PV depends on. Changes in the irradiance and the temperature cause a variation in voltage and current respectively.

The PV manufacturers are utilized to obtain the module parameters as short circuit current $\left(I_{S C}\right)$, open circuit voltage ( $\left.V_{O C}\right)$, maximum power $\left(P_{\max }\right)$ and fill factor $(F F)$. This is executed under a standard test conditions which is irradiance equal to $1000 \mathrm{~W} / \mathrm{m}^{2}$, cell temperature is $25^{\circ} \mathrm{C}$. However, these conditions are sometimes far from the daily working conditions. As a result, a low cost, precise characterizing system is required to examine the PV performance during its working conditions. A system for measuring the $\mathrm{I}-\mathrm{V}$ characteristic for seven PV modules, is introduced in [1]. A set of resistors are connected together and are controlled by relays and switches. In [2], a simple electronic load for testing a set of PV panels using linear metal oxide field effect transistors (MOSFETs) is presented. The proposed set up under test gives the current versus voltage and power versus voltage characteristics of PV panels by quickly scanning the load. A developed system is published in [3] based on that in [2]. This system uses LABVIEW with Microcontroller unit connected to the electronic load circuit providing higher accuracy and lower tracing time. The design is considered low cost system but it still was complex. In [4], the electronic circuit was enhanced by using a DAQ system with LABVIEW application for controlling the MOSFET gate-source voltage. For enhancing the I-V and P-V characteristic that was shown in [4], a new design for the electronic circuit is suggested which consist of MOSFET controlled by means of an innovative sweeping gate-source voltage. These system shows a high tracing frequency but with low accuracy. In order to improve the tracing of the I-V characteristics, an oscilloscope with pulse width modulation circuit is presented in [5]. The circuit was developed in [6] with low-cost DAQ system in order to trace the I-V characteristic accurately.

In this paper, an improved electronic load circuit is presented to characterize a PV module by tracing their I-V and P-V characteristic curves. Power MOSFET is used as an electronic load for tracing the current voltage characteristics by varying its gate source voltage $\left(V_{G S}\right)$ through generating a signal using a low cost NI-DAQ. Performing PWM using LABVIEW is considered as an innovation with respect to the work in $[4,6]$ since it provides the same accuracy in [6], but with lower cost and less sophistication.

\section{MODELLING AND SIMULATION}

A numerical model based on Comsol Multiphysics [7] and Matlab simulation tool for a PV module is introduced as shown in Fig. 1. This model is used as a verification tool for our experimental results. For optical modeling Maxwell's 
equations are solved in three dimensions to calculate the absorption coefficient of the $\mathrm{Si}$ and AM1.5G is assumed [8].On the other hand, drift diffusion model is considered for the semiconductor modeling of the device where carrier transport is assumed to be in one direction including both bulk and surface recombination [9].

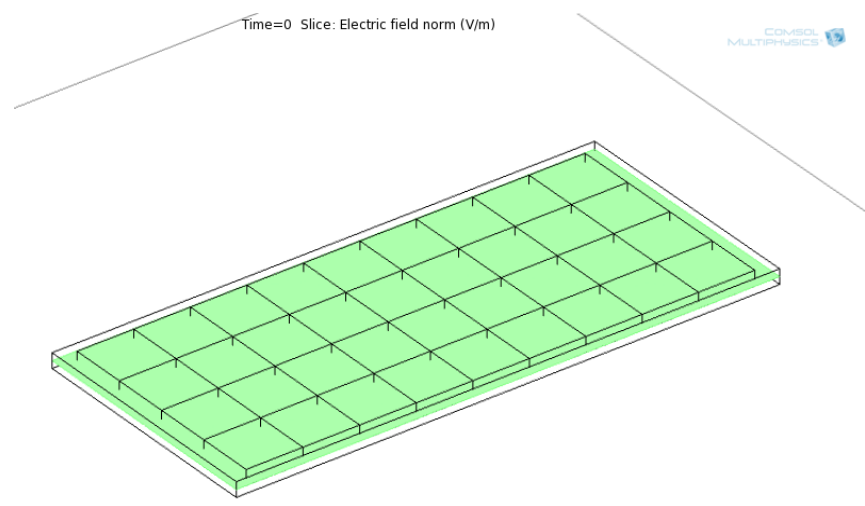

$x^{2}+x$

Fig1. PV module using in COMSOL

The operation of most semiconductor devices, including solar cells, can be described by the so-called semiconductor device equations, first derived by Van Roosbroeck as given in [10]. A generalized form of these equations is given below.

$$
\nabla \varepsilon \mathcal{E}=\mathrm{q}(\mathrm{p}-\mathrm{n}+\mathrm{N})
$$

This is a form of Poisson's equation, where $\mathrm{N}$ is the net charge due to dopants and other trapped charges. The hole and electron continuity equations are

$$
\begin{aligned}
& \nabla \mathrm{J}_{\mathrm{p}}=\mathrm{q}\left(\mathrm{G}-\mathrm{R}_{\mathrm{p}}-\frac{\partial \mathrm{p}}{\partial \mathrm{t}}\right)(2) \\
& \nabla \mathrm{J}_{\mathrm{n}}=\mathrm{q}\left(\mathrm{R}_{\mathrm{n}}-\mathrm{G}+\frac{\partial \mathrm{n}}{\partial \mathrm{t}}\right)(3)
\end{aligned}
$$

Where $G$ is the optical generation rate of electron-hole pairs and $R_{p}$ and $R_{n}$ are the recombination rate for both holes and electrons, Thermal generation is included in $R_{p}$ and $R_{n}$. The hole and electron current densities are given by

$$
\begin{aligned}
& \mathrm{J}_{\mathrm{p}}^{\text {total }}=-\mathrm{q} \mu_{\mathrm{p}} \mathrm{p} \nabla\left(\phi-\phi_{\mathrm{p}}\right)+\mathrm{KT} \mu_{\mathrm{p}} \nabla \mathrm{p}(4) \\
& \mathrm{J}_{\mathrm{n}}^{\text {total }}=-\mathrm{q} \mu_{\mathrm{n}} \mathrm{n} \nabla\left(\phi+\phi_{\mathrm{n}}\right)+\mathrm{KT} \mu_{\mathrm{n}} \nabla \mathrm{n}(5)
\end{aligned}
$$

Where $\phi_{\mathrm{p}}$ and $\phi_{\mathrm{n}}$ are the so-called band parameters that account for degeneracy and a spatially varying band gap and electron affinity these terms were ignored in the preceding discussion and can usually be ignored in no degenerate homostructure solar cells.

\section{EXPERIMENTAL SETUP}

The I-V characteristics of a 150 Watt polycrystalline PV module [11] were traced using the circuit shown in Fig. 2 with a power MOSFET (IRFP260N) as a varying electronic load. The I-V and P-V characteristics of a polycrystalline PV module were traced using the circuit shown in Fig. 2. The circuit is based on MOSFET IRFP260N as a varying electronic load with heat sink to dissipate the power. The characteristics of the MOSFET in both linear and saturation region are described respectively by [12].

$$
\begin{aligned}
& I_{D}=K_{N}\left(2\left(V_{G S}-V_{T}\right) V_{D S}-V_{D S}^{2}\right) \\
& I_{D}=K_{N}\left(V_{G S}-V_{T}\right)^{2}
\end{aligned}
$$

Three power MOSFETs are used to tolerate the maximum power of 150 Watt as shown in figure 2. The MOSFETs are operated in its ohmic region where the resistive value is controlled through the gate voltage which is generated by a NI-DAQ 6009. Where $V_{G S}$ is the gate-source voltage, $V_{D S}$ the drain-source voltage, $K_{N}$ the device constant, $V_{T}$ the threshold voltage and $I_{D}$ the drain current of the MOSFET. As $V_{G S}$ is less than the threshold voltage $V_{T}$, the MOSFET will be OFF. When $V_{G S}$ is increased above $V_{T}$ the MOSFET will operate in the saturation region and the drain current rises quadratically with $V_{G S}$. At lower solar module voltage the operating point of the MOSFET shifts to the linear region where the drain current changes linearly with $\mathrm{V}_{\mathrm{GS}}$. Thus, by sweeping the gate voltage the operating point of the MOSFET sweeps the I-V characteristic of the module between $V_{O C}$ and Isc. Pulse width modulation (PWM) process is used to control the gate voltage as illustrated in Fig. 3. The PWM frequency is set to $1 \mathrm{KHz}$ and a saw-tooth signal is used to vary the pulse duration. The modulation process is developed by connecting the saw-tooth generator with the duty cycle adjuster of the square wave generator. The saw-tooth frequency is adjusted to be $1 \mathrm{~Hz}$ so that a complete characterization process occurs in $1 \mathrm{sec}$ with 1000 samples. In order to isolate the DAQ to avoid any loading problem, a buffer is implemented using LM741 with an adjustable gain to calibrate the operating point according to the required gate voltage. 


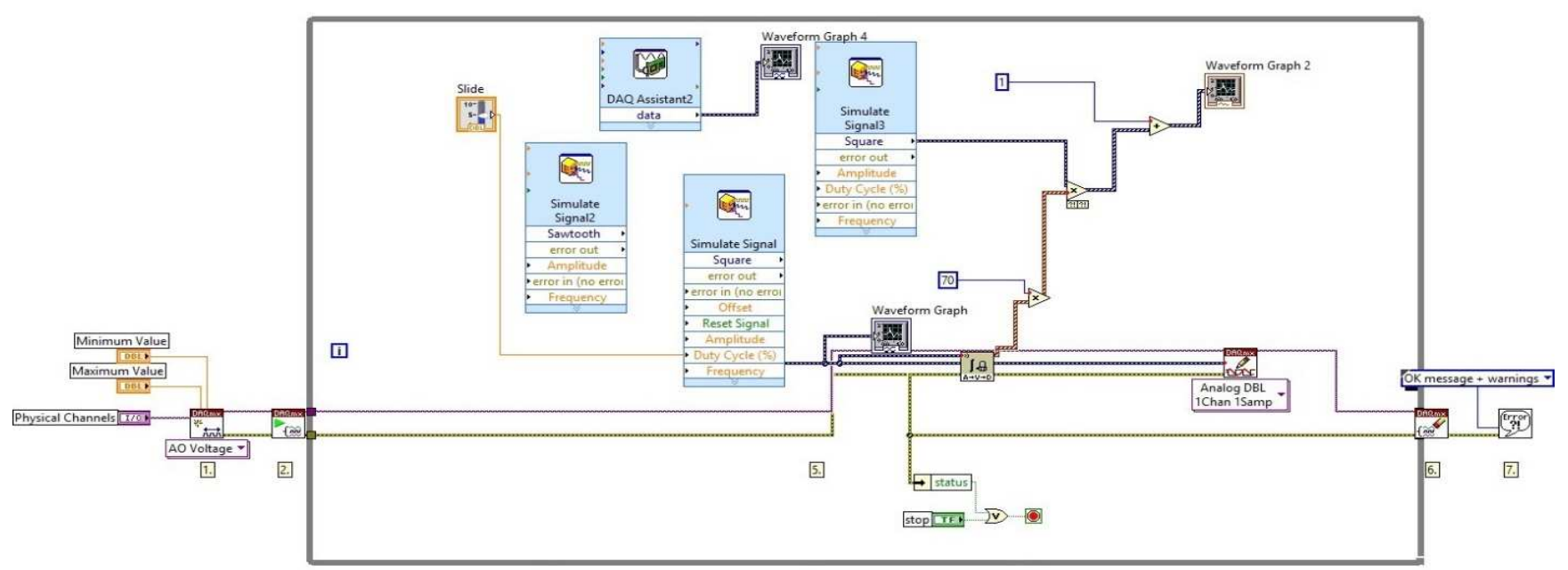

Fig. 2:.Electronic load circuit

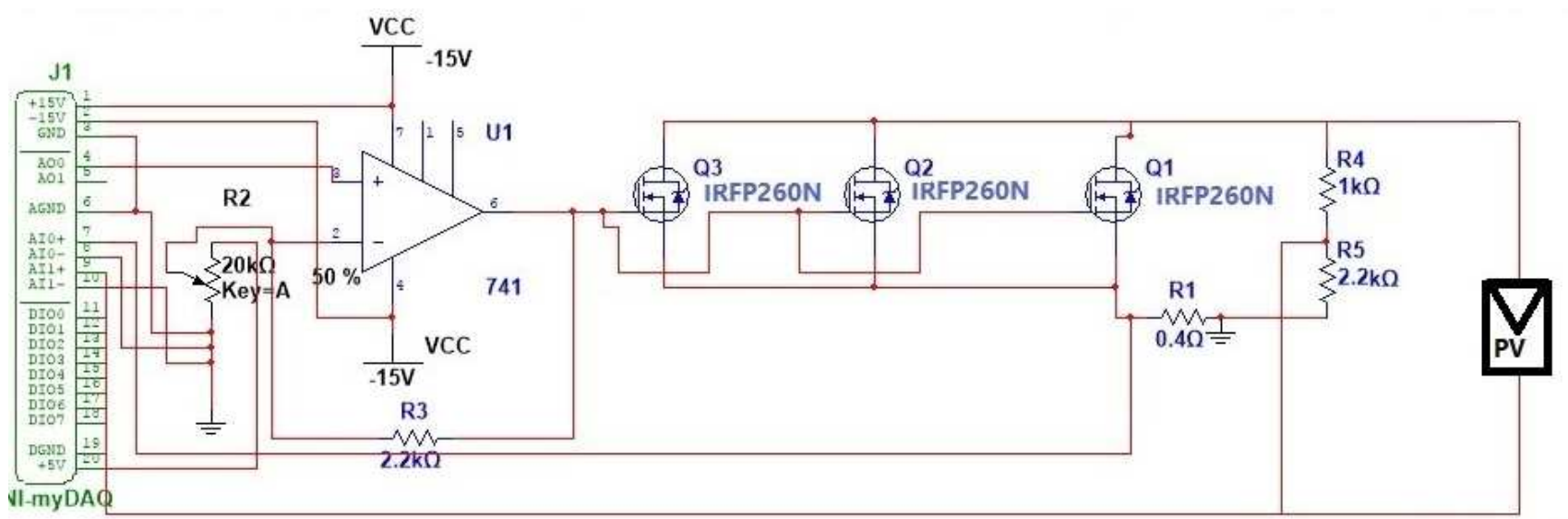

Fig. 3:.LABVIEW block diagram for PWM.

In order to acquire the PV voltage and current, two acquiring circuits is used. For voltage, a potential divider is inserted parallel to the PV with relativity high resistive value with respect to the MOSFETs equivalent resistance. Regarding Current, a high power low resistive value resistance is embedded in series with the PV module. A low resistive value resistance is chosen to avoid its loading effect. A mechanical setup is designed and implemented on the roof of the British University in Egypt (BUE) with an inclination angle of $30^{\circ}$ with respect to the normal direction as shown in Fig. 4.

\section{EXPERIMENTAL RESULTS AND DISCUSSION}

Experimental results are taken in more than one day and some of them are chosen to be presented in this work. A comparison between experimental, simulation results and the standard curves is illustrated in Fig. 5 using the numerical model described above. These output characteristics are taken under irradiance $620 \mathrm{~W} / \mathrm{m}^{2}$ where the maximum power observed was about $100 \mathrm{~W}, \mathrm{I}_{\mathrm{SC}}=8 \mathrm{~A}$ and $\mathrm{V}_{\mathrm{OC}}=20 \mathrm{~V}$. The results shows a great accordance between the simulation model and the experimental data which can be considered as a validation for our new approach in characterizing the PV module using a LABVIEW PWM. On the other hand, both experimental and simulation results are a little bit far from the standard curves as the measurements condition was far from the ideal one. This difference is not only in the irradiance variation from $1000 \mathrm{~W} / \mathrm{m}^{2}$ in case of standard test condition to $620 \mathrm{~W} / \mathrm{m}^{2}$ in practical measurement, but also due to the power losses in connections and acquiring system. This power losses can be easily detected from the reduction in the open circuit voltage from 22.5 volt in standard curve to about 20 volt in the practical measurements. This voltage drop could be reduced by using lower power consumption circuits for voltage and current acquiring and this is considered for future work. 


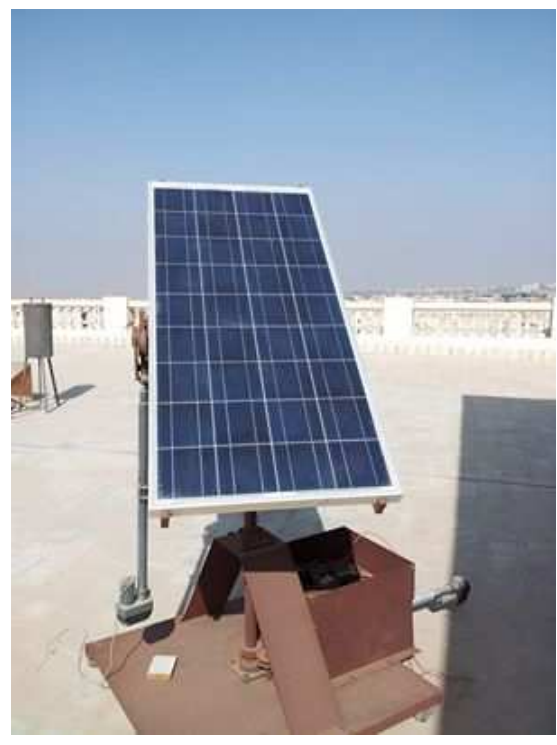

Fig. 4: Experimental setup for a 150 watt PV module.
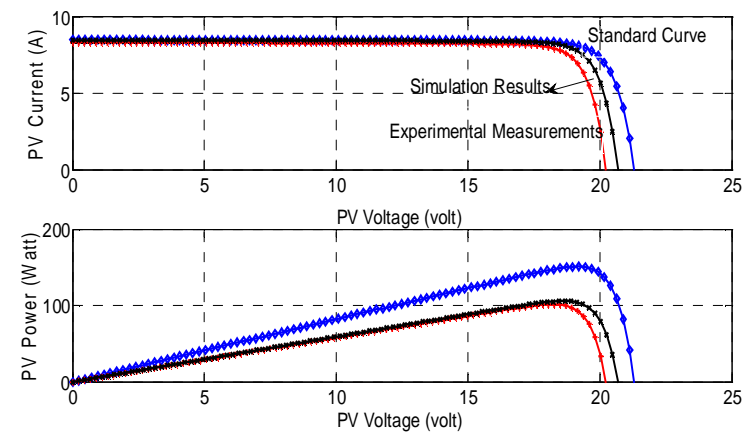

Fig.5: I-V and P-V curves for a 150 Watt PV module (a) under standard test conditions (b) Simulation results and (c) experimental results.

\section{CONCLUSIONS}

The work in this paper presents a new approach in characterizing a 150 Watt PV module using electronic load circuit driven by pulse width modulator. Experimental results are taken and compared with a precise developed simulator based on Comsol Multiphysics. The experimental results shows high accordance with simulation results. The suggested systems shows a very high accuracy compared with the previous published techniques with lower cost and complicity.

\section{ACKNOWLEDGEMENTS}

This work is funded by the British University in Egypt (BUE). The authors acknowledge the valuable support of Prof. Hani Ghali, the vice-dean of the faculty of Engineering, throughout the work.

\section{REFERENCES}

[1]. VanDyk E.E., Gxasheka A. R., Meyer E.L. Monitoring Current-Voltage Characteristics and Energy Output of Silicon Photovoltaic Modules. ELSEVIER, Renewable Energy 30, 2005. p. 399-411,

[2]. Kuai Y., YuvarajanS.,An Electronic Load for Testing Photovoltaic Panels. ELSEVIER, Journal of Power Sources 154, 2006. P.308-313.

[3]. Atia Y., Zahran M., Al-Hossain A. Solar Cell Emulator and Solar Cell Characteristics Measurements in Dark and Illuminated Conditions. Wseas Transactions On Systems And Control, Issue 4, Volume 6, ISSN: 1991-8763. April 2011.

[4]. A. Sahbal, N.Hassan, M. Abdelhameed, A. Zekry, Experimental Performance Characterization of Photovoltaic Modules Using DAQ, TerraGreen 13 International Conference 2013 - Advancements in Renewable Energy and Clean Environment, Energy Procedia 36 (2013) 323 - 332

[5]. Leite V., Chenlo F.An Improved Electronic Circuit for Tracing the I-V Characteristics of Photovoltaic Modules and Strings. In Proc. of the International Conference on Renewable Energies and Power Quality (ICREPQ'10), March 23-25, 2010.

[6]. Leite V., Batista J., Chenlo F., Afonso J. Low-Cost Instrument for Tracing Current-Voltage Characteristics of Photovoltaic Modules. in Proc. of the International Conference on Renewable Energies and Power Quality (ICREPQ'12), March 28-30, 2012.

[7]. Comsol, Version 4.2, http://www.comsol.com.

[8]. Reference solar spectral irradiance: Air mass 1.5, National Renewable Energy Lab. http://rredc.nrel.gov/solar/spectra/am1.5/. Accessed 29 March2011.

[9]. Abdellatif, S., Kirah, K. 'Nanowire photovoltaic efficiency enhancement using plasmonic coupled nano-fractal antennas ' Optics Letters, Vol. 38, Issue 18, pp. 3680-3683, 2013.

[10]. Abdellatif, S, Kirah, K., Ghalli, H, and Anis, W." Spectral and Spatial Distributed Nanowire Array Enhanced by Nanoring Optical Antenna ' Optical Materials Express, Vol. 2 Issue 10, pp.1432-1436 (2012)

[11]. ISTARSOLAR, http://www.istarsolar.com.

[12]. Hambley A. R. Electronics. 2nd edition. Prentice Hall. Upper Saddle River. New Jersey 07458. 2000.

\section{BIOGRAPHIES}

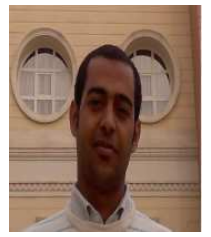

IbrahemM. Mahmoud: received the B.Sc. degree in Electrical Power and Machines from Helwan University, Cairo, Egypt, in 2008 and a M.Sc. Student in Renewable Energy at British University in Egypt, Cairo, Egypt, Currently. Currently He is enrolled as a demonstrator in the Electrical engineering department in the British University in Egypt (BUE). His research interests lie in the field of renewable energy especially PV and Wind 
energy systems. He is also involved in more than one funded project in the renewable energy field.

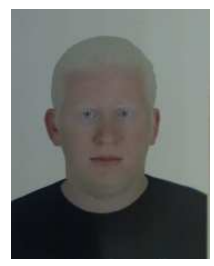

Sameh O. Abdellatif: received the B.Sc. degree in Electronics and communication from Ain Shams University, Cairo, Egypt, in 2009 and the M.Sc. degree in Semiconductor nano-structures from Ain Shams University, Cairo, Egypt, in 2012. Currently $\mathrm{He}$ is enrolled as an assistant lecturer in the Electrical engineering department in the British University in Egypt (BUE) and a research assistant in the Egypt Nanotechnology Center (EGNC). His research interests lie in the field of modeling and simulation of inorganic semiconductor nano-structures where he published some scientific papers in the last two years.

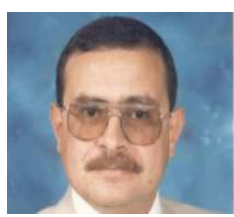

Tarek S. Abdel-Salam: Got his B.Sc. and M.Sc. from Ain Shams University, Cairo, Egypt on 1980 and. His $\mathrm{PhD}$ was from University of Windsor, Windsor, ON, Canada. On 1994. His research area of interest is power system analysis and exposure to electromagnetic fields. Currently he acts as the heads of electrical engineering department in the British University in Egypt (BUE).

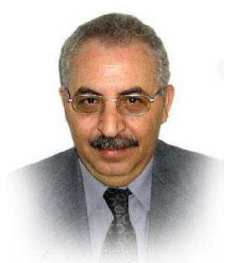

Osama E. Abdellalatif: received the B.Sc. degree in Mechanical Engineering from Cairo University, Cairo, Egypt, in 1979 and the M.Sc. Degree from Cairo University, Faculty of Engineering, Aeronautical Department, 1985. His PhD was fromUniversity of Zagazig and City University, London, U.K., in 1990. His research interests lie in the field of renewable energy especially PV and Wind energy systems. He is enrolled as a professor in the mechanical engineering department in Shoubra Faculty of Engineering, Benha University. 